\title{
Thermodynamic prediction of proton and hydrogen atom abstraction in dehydroascorbic acid and its bicyclic form
}

\author{
Dagmar Štellerová, Vladimír Lukeš \\ Institute of Physical Chemistry and Chemical Physics, Slovak University of Technology in Bratislava, \\ Radlinského 9, SK-812 37 Bratislava, Slovakia \\ dagmar.stellerova@stuba.sk
}

\begin{abstract}
Conformation analysis of dehydroascorbic acid and its bicyclic form was performed using the density functional theory. For the energetically preferred conformations, ionization potentials (IP) and bond dissociation enthalpies (BDE) were calculated using the B3LYP functional and 6-311++ $\mathrm{G}^{* *}$ basis set. The effects of aqueous solution were estimated using the solvation model based on density (SMD) and the polarizable continuum model (IEF-PCM). The obtained results were compared with available experimental data for reference L-ascorbic acid (vitamin C). Our calculations indicate that the investigated bicyclic metabolic product of vitamin $\mathrm{C}$ can also exhibit limited radical scavenging ability due to the thermodynamically preferred dissociation of tertiary $-\mathrm{CH}$ bonds.
\end{abstract}

Keywords: vitamin C, oxidation product, radical scavenger, $\mathrm{p} K_{\mathrm{a}}$ values

\section{Introduction}

Chemistry of L-ascorbic acid (AA, vitamin C) has been widely studied due to its biological importance (Bendich and Langseth, 1995). This water-soluble organic acid is a well-known radical scavenger and an antioxidant in living systems. Although the molecule of vitamin C normally loses only one electron, two electron oxidations can be observed under in vitro electrochemical conditions (Deakin et al., 1986). Apart from being a distinguished reducing agent of reactive radical species, vitamin $\mathrm{C}$ is a cofactor in the enzymatic biosynthesis of collagen, catecholamine, carnitine, and peptide neurohormones. It is transported across the blood-brain barrier in its oxidized form, called dehydroascorbic acid (A). This molecule is also involved in the oxidation of low-density lipoprotein (Wilson, 2002). Furthermore, dehydroascorbic acid has found its purpose in pharmaceutical industry. It has been used as a biochemical marker of oxidative stress in clinical investigations, as vitamin $\mathrm{C}$ dietary supplement or as a mucolytic drug called Ascoxal (Fisher and Ten Pas, 1966).

Since the vitamin $\mathrm{C}$ structure determination in 1930 s, its oxidation mechanism, which is complex and still not fully understood, has been studied (Tu et al., 2017). Thermodynamics and kinetics of reactions associated with the mechanism have been studied by numerous experimental and theoretical research groups. Vitamin $\mathrm{C}$ is in these reactions oxidated to one-electron form - shortlived ascorbate radical, or to fully oxidized twoelectron A form. Dehydroascorbic acid can also be formed by oxidation of the ascorbate radical or by the disproportionation reaction between two ascorbate radicals. Although the structure of $\mathbf{A}$ is generally presented as a molecule with one nonaromatic ring (Fig. 1), this structure is known to be energetically unstable in water. It is assumed that the structure of dehydroascorbic acid is an intermediate which immediately goes through ring closure, and along with hydration, forms a stable bicyclic form $\mathbf{B}$ (Fig. 1). To date, structures associated with the oxidation products of vitamin $\mathrm{C}$ have been studied extensively in many theoretical and experimental works (Bielski et al., 1981; Bielski et al., 1985; Kurata and Nishikawa, 2000). Recently, $\mathrm{Tu}$ and Njus (Tu et al., 2017; Njus et al., 2020) explored theoretically the oxidation mechanism of ascorbic acid and its reaction with superoxide determining the lowest energy conformations of oxidation products and deprotonated forms of ascorbic acid. In agreement with nuclear magnetic resonance measurements, the bicyclic hydrated isomer of dehydroascorbic acid was found to be the most stable structure of the fully oxidized form of ascorbic acid in aqueous solution. The suggested Pourbaix diagrams and calculated $\mathrm{p} K_{\mathrm{a}}$ values were in good agreement with the available experimental values.

The mentioned experimental and theoretical works suggest that the antioxidant activity of the studied molecules is related to the dissociation of hydroxyl groups. On the other hand, thermodynamics of the deprotonation reaction from tertiary - $\mathrm{CH}$ bonds has not been discussed or analyzed. Therefore, we decided to theoretically investigate the thermo- 


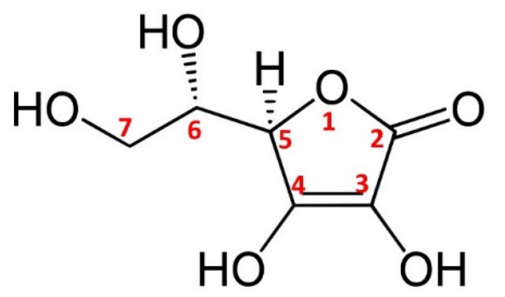

AA

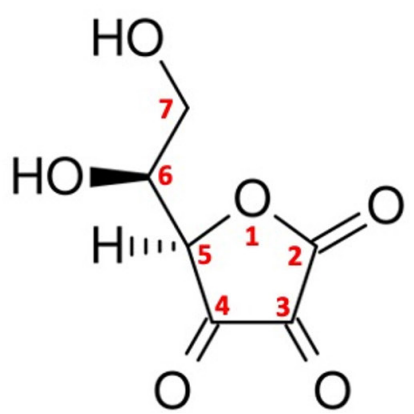

A

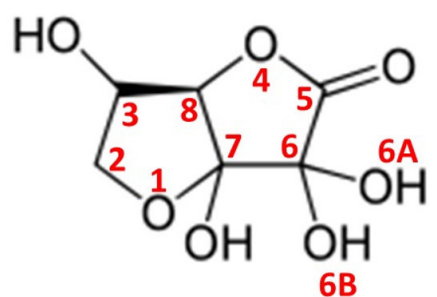

B

Fig. 1. Schematic structure and atom numbering of L-ascorbic acid (AA), dehydroascorbic acid (A) and its bicyclic form $(\mathbf{B})$.

dynamics of hydrogen atom and proton abstraction from the tertiary methyl - $\mathrm{CH}$ groups of dehydroascorbic acid and its bicyclic hydrated isomer (Fig. 1). Partial aims of this study are: (1) perform conformational analysis for the gas-phase and water environment; (2) calculate the reaction enthalpies and Gibbs energies at the room temperature and (3) evaluate the corresponding $\mathrm{p} K_{\mathrm{a}}$ values. The obtained results were compared with published theoretical and available experimental data.

\section{Computational Details}

All quantum chemical calculations were carried out by the Gaussian 16 software package (Frisch et al., 2016). Visualizations of the parent molecules, their radicals and ions were designed in the Molekel program package (Flukiger et al., 2002). Geometries were optimized using the B3LYP (Lee et al., 1988; Becke, 1988) DFT hybrid functional with the $6-311++\mathrm{G}^{* *}$ basis set (Binkley et al., 1980). Vibrational frequency calculations were included at the same level of theory to confirm that the optimised structures were real stationary points and no imaginary vibrations were present. As both dehydroascorbic acid structures have numerous conformers according to the alkyl chain and several rotatable hydroxyl groups, these were investigated first. The lowest-energy structures were used to obtain gas-phase enthalpies and Gibbs free energies of the radicals/ions at $p=101325 \mathrm{~Pa}$ and $T=298.15 \mathrm{~K}$. Furthermore, these structures were used as starting points for re-optimization in aqueous solution to obtain more accurate $\mathrm{p} K_{\mathrm{a}}$ values. Solvent contribution was applied using SMD (Marenich et al., 2009) and IEF-PCM (Tomasi et al., 2005) polarizable continuum models. The combination of B3LYP with implicit solvent models offers relevant prediction of thermodynamic quantities (Michalík and Lukeš, 2016).

\section{Results and Discussion}

The selected energetically preferred structures of L-ascorbic acid (AA), dehydroascorbic acid (A) and its bicyclic form (B) are depicted in Fig. 2. Orientation of the hydroxyl substituents allows the formation of intramolecular hydrogen bonds (see Tab. 1) which contribute to the relative stability of their geometry. For reference L-ascorbic acid, the selected conformation was taken from Tu and Schlegel (2017). The energetically preferred geometry is represented by a planar five-membered ring and a 1,2-dihydroxyethyl chain bent in the direction of the ring forming three stable hydrogen bonds between the groups. The dehydroascorbic acid A molecule contains a planar furan-2,3,4(5H)-trione moiety and an 1,2-dihydroxyethyl group. Multiple possible rotations of the 1,2-dihydroxylethyl group around C5 - C6 and C6 - C7 bonds with respect to the planar ring lead to eighteen possible conformers. For molecule $\mathbf{B}$, the presence of bicyclic rings reduces the number of possible conformations. With respect to the orientation of hydroxyl groups, eight possible structures were identified. In case of vitamin C, the studied conformation contains three intramolecular hydrogen bonds. The shortest bond length is that of $\mathrm{C} 4 \mathrm{OH}$...OC7, e.g. $1.757 \AA$ in the gas-phase. The most stable conformation A contains only two hydrogen bonds between $\mathrm{C} 6 \mathrm{OH}$... OC4 atoms, with the length of $2.285 \AA$, and between $\mathrm{C} 6 \mathrm{OH}$... OC7 atoms, with the length of 2.818 $\AA$. The oxolane rings of bicyclic $\mathbf{B}$ molecule are not planar but bent to each other, leaving groups $\mathrm{OH} 7$ and $\mathrm{OH} 3$ behind their plane. Therefore, the most energetically preferred B conformer possesses eight internal hydrogen bonds. Compared with the gas-phase geometries, the inclusion of implicit solvent models affects the intramolecular bond lengths.

Chemical structure of the studied molecules has direct impact on the homolytic or heterolytic bond 


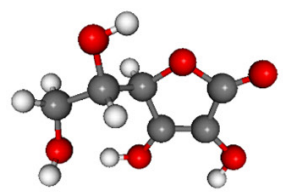

AA

(-684.991461 hartree)

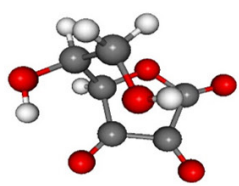

A

(-683.754712 hartree)

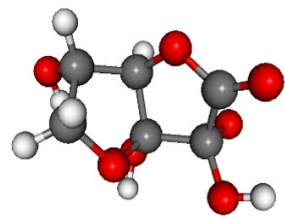

B

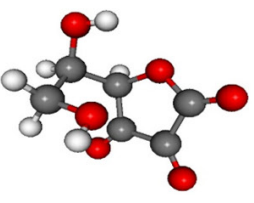

A1

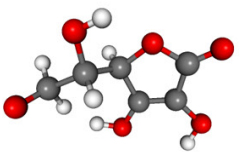

AA(7-OH)

(-684.4040538 hartee)

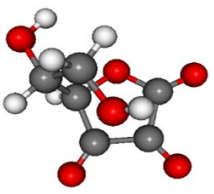

A2

(-683.752188 hartree)

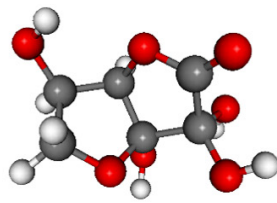

B 1

(-760.240106 hartree)

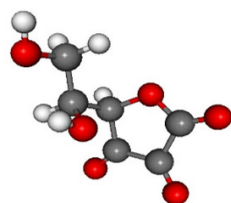

A3

(-683.754028 hartree)

(-760.240071 hartree)

Fig. 2. Optimal gas-phase B3LYP/6-311++ $\mathrm{G}^{* *}$ geometries of energetically preferred conformations of studied molecules. Conformation $\mathbf{A A}(\mathbf{7 - O H})$ with two intramolecular hydrogen bonds was used for the evaluation of $P A$ and $\mathrm{p} K_{\mathrm{a}}$ values. Values in parentheses represent the corresponding electronic energies in hartree.

dissociation. For further thermodynamic calculations of the most stable state and its derivates, geometries of conformer $\mathbf{A}$ and $\mathbf{B}$ were selected (see Fig. 2). Thermodynamics of homolytic dissociation of chemical bonds can be estimated from the bond dissociation enthalpies (BDEs) which represent a one-step mechanism of hydrogen atom transfer (HAT). This quantity can be calculated as

$$
\mathrm{BDE}=H\left(\mathrm{~A}^{\bullet}\right)+H\left(\mathrm{H}^{\bullet}\right)-H(\mathrm{~A}-\mathrm{H})
$$

where $H\left(\mathrm{~A}^{*}\right)$ stands for the total enthalpy of formed radical, $H\left(\mathrm{H}^{*}\right)$ for total enthalpy of hydrogen atom, and $H(\mathrm{~A}-\mathrm{H})$ is the total enthalpy of the molecule. The total gas-phase enthalpy of hydrogen atom is $-1306 \mathrm{~kJ} \mathrm{~mol}^{-1}$ and the contribution of the solvation enthalpy in water is $-4 \mathrm{~kJ} \mathrm{~mol}^{-1}$ (Rimarčík et al., 2010).

For reference L-ascorbic acid (see Tab. 2), the gasphase BDEs for possible radical structures formed from the hydroxyl groups and tertiary methyl group are in the range of $332 \mathrm{~kJ} \mathrm{~mol}^{-1}$ to $450 \mathrm{~kJ} \mathrm{~mol}^{-1}$. The values of $\mathrm{C} 3-\mathrm{OH}$ and $\mathrm{C} 5-\mathrm{H}$ are in the best agreement with the available experimental value of $326.4 \mathrm{~kJ} \mathrm{~mol}^{-1}$ (Warren et al., 2010). The homolytic dissociation of hydroxyl groups located at the side 1,2-dihydroxylethyl substituent is less preferable. For AA and $\mathbf{A}$ molecules, the gas-phase
Tab. 1. Calculated B3LYP/6-311++ $\mathrm{G}^{* *}$ gas-phase, SMD and IEF-PCM intramolecular hydrogen bond lengths of most stable conformers.

\begin{tabular}{|c|c|c|c|c|}
\hline & \multirow[b]{2}{*}{ Substituent } & \multicolumn{3}{|c|}{$\mathbf{R}(\mathbf{O} \cdots \mathbf{H}) / \AA$} \\
\hline & & Gas-phase & SMD & IEF-PCM \\
\hline \multirow{3}{*}{$\mathbf{A A}$} & C3OH $\cdots . \mathrm{OC} 4$ & 2.599 & 2.688 & 2.649 \\
\hline & С4OH $\cdots . \mathrm{OC7}$ & 1.757 & 1.661 & 1.689 \\
\hline & С6OH $\cdots .01$ & 2.214 & 2.392 & 2.295 \\
\hline \multirow{2}{*}{$\mathbf{A}$} & С6OH... OC4 & 2.285 & 2.270 & 2.470 \\
\hline & С6OH… OC7 & 2.818 & 2.724 & 2.715 \\
\hline \multirow[t]{8}{*}{ B } & С3OH $\cdots . \mathrm{OC7}$ & 2.422 & 2.762 & 2.525 \\
\hline & С3OH $\cdots .01$ & 2.977 & 3.111 & 3.036 \\
\hline & C7OH $\cdots O 1$ & 2.358 & 2.452 & 2.394 \\
\hline & С7OH $\cdots$ OC6B & 3.113 & 3.093 & 3.157 \\
\hline & С6АOH $\cdots$ OC7 & 2.273 & 2.229 & 2.238 \\
\hline & С6АОН … OC6B & 2.672 & 2.718 & 2.705 \\
\hline & С6ВОН …ОС5 & 2.572 & 2.718 & 2.695 \\
\hline & С6ВОН...ОС6А & 2.623 & 2.531 & 2.545 \\
\hline
\end{tabular}

BDEs are higher by about $100 \mathrm{~kJ} \mathrm{~mol}^{-1}$. Interestingly, molecule $\mathbf{A}$ gas-phase BDEs for homolytic splitting of $\mathrm{C} 5-\mathrm{H}$ bond is $342 \mathrm{~kJ} \mathrm{~mol}^{-1}$. The energetically preferred homolytic cleavage of $\mathrm{C}-\mathrm{H}$ 
bonds was predicted for various $\Delta 5$ - and $\Delta 7$-sterols by Lengyel et al. (Lengyel et al., 2012) and Škorňa et al. (Škorňa et al., 2014). Considering the implicit solvent models, the BDE values slightly deviate ( 1 to $5 \mathrm{~kJ} \mathrm{~mol}^{-1}$ ) in most calculations but there are more significant differences $\left(\sim 10 \mathrm{~kJ} \mathrm{~mol}^{-1}\right)$ in molecule AA hydroxyl groups $\mathrm{C} 3-\mathrm{OH}$ and $\mathrm{C} 6-\mathrm{OH}$, molecule A $\mathrm{C} 6-\mathrm{OH}$ and molecule B C3- $\mathrm{H}$ and $\mathrm{C} 7-\mathrm{OH}$ groups.

Abstraction of hydrogen atom is also possible via a two-step mechanism denoted as single electron transfer followed by proton transfer (SET-PT). In the first step, the electron is abstracted from the molecule and the proton transfer reaction results in a cation radical. Thermodynamics of the first step of the SET-PT mechanism is described by ionization potential (IP),

$$
I P=H\left(\mathrm{~A}-\mathrm{H}^{\cdot+}\right)+H\left(\mathrm{e}^{-}\right)-H(\mathrm{~A}-\mathrm{H})
$$

where $H\left(\mathrm{~A}-\mathrm{H}^{\cdot+}\right)$ is total enthalpy of radical cation, and $H\left(\mathrm{e}^{-}\right)$is enthalpy of electron. The total gasphase enthalpy of electron is $3.145 \mathrm{~kJ} \mathrm{~mol}^{-1}$ and the contribution of the solvation enthalpy in water is $-105 \mathrm{~kJ} \mathrm{~mol}^{-1}$ (Rimarčík et al., 2010).

Predicted gas-phase ionization potential values for $\mathbf{A A}$ and $\mathbf{A}$ molecules are $794.3 \mathrm{~kJ} \mathrm{~mol}^{-1}$ and $872.8 \mathrm{~kJ} \mathrm{~mol}^{-1}$, respectively. The presence of two cyclic moieties in $\mathbf{B}$ molecule increases the IPs by about $11 \mathrm{~kJ} \mathrm{~mol}^{-1}$. Entering the solvent models, the values drop to $557.3 \mathrm{~kJ} \mathrm{~mol}^{-1}$ (SMD) and $581.7 \mathrm{~kJ} \mathrm{~mol}^{-1}$ (IEF-PCM). The minimum value appears to be the SMD one. In general, vitamins with higher $I P$ values are more susceptible to ionization and they have stronger antioxidant potential (Pandithavidana and Jayawardana, 2019).

Thermodynamics of heterolytic dissociation of chemical bonds can be described using through proton affinity (PA), which is for the anion formation defined as:

$$
P A=H\left(\mathrm{~A}^{-}\right)+H\left(\mathrm{H}^{+}\right)-H(\mathrm{~A}-\mathrm{H})
$$

where $H\left(\mathrm{~A}^{-}\right)$is enthalpy of anion and $\mathrm{H}\left(\mathrm{H}^{+}\right)$is total enthalpy of proton. The total gas-phase enthalpy of proton is $6.197 \mathrm{~kJ} \mathrm{~mol}^{-1}$ and the contribution of the solvation enthalpy is $-1090 \mathrm{~kJ} \mathrm{~mol}^{-1}$ (Rimarčík et al., 2010).

Values collected in Tab. 2 indicate show significant differences in $P A$ s between gas-phase and solvent calculations, as expected for the deprotonation mechanism. In case of the $\mathbf{A A}$ anion with starting geometry including a deprotonated 7-OH group, the resulting calculated geometry belongs to the anion with deprotonated 4-OH group. This proton transfer from 4-OH group to the negatively charged 7-O atom results in the presence of a hydrogen bond in the parent AA conformation (see Tab. 1). The stable geometry of $\mathbf{A A}\left(\mathbf{7 - \mathbf { O } ^ { - }}\right)$ anion was reached

Tab. 2. Ionization potentials $(I P)$, bond dissociation enthalpies $(B D E)$ and proton affinities $(P A)$ calculated

\begin{tabular}{|c|c|c|c|c|c|c|c|c|c|}
\hline & \multicolumn{3}{|c|}{$I P / \mathrm{kJ} \mathrm{mol}^{-1}$} & \multicolumn{3}{|c|}{$B D E / \mathrm{kJ} \mathrm{mol}^{-1}$} & \multicolumn{3}{|c|}{$P A / \mathrm{kJ} \mathrm{mol}^{-1}$} \\
\hline & \multirow[t]{2}{*}{ Gas } & \multicolumn{2}{|c|}{ Water } & \multirow[t]{2}{*}{ Gas } & \multicolumn{2}{|c|}{ Water } & \multirow[t]{2}{*}{ Gas } & \multicolumn{2}{|c|}{ Water } \\
\hline & & SMD & IEF-PCM & & SMD & IEF-PCM & & SMD & IEF-PCM \\
\hline $\mathbf{A A}$ & 794 & 462 & 498 & & & & & & \\
\hline $\mathbf{A}$ & 873 & 557 & 582 & & & & & & \\
\hline B & 889 & 538 & 580 & & & & & & \\
\hline $\mathbf{A A}(3-\mathrm{OH})$ & & & & 332 & 319 & 316 & 1421 & 109 & 120 \\
\hline $\mathbf{A A}(4-\mathrm{OH})$ & & & & 335 & 333 & 334 & 1305 & 67 & 61 \\
\hline $\mathbf{A A}(6-\mathrm{OH})$ & & & & 450 & 436 & 435 & 1472 & 159 & 178 \\
\hline $\mathbf{A A}(7-\mathrm{OH})^{*}$ & & & & 426 & 432 & 430 & 1459 & 169 & 179 \\
\hline $\mathbf{A A}(5-\mathbf{H})$ & & & & 334 & 341 & 336 & 1476 & 196 & 200 \\
\hline $\mathrm{A}(6-\mathrm{OH})$ & & & & 440 & 432 & 430 & 1452 & 150 & 164 \\
\hline $\mathrm{A}(7-\mathrm{OH})$ & & & & 430 & 430 & 430 & 1351 & 84 & 89 \\
\hline$A(5-H)$ & & & & 342 & 343 & 341 & 1334 & 80 & 80 \\
\hline B(3-OH) & & & & 429 & 431 & 427 & 1414 & 150 & 148 \\
\hline $\mathbf{B}\left(6-\mathrm{OH}^{\mathrm{A}}\right)$ & & & & 394 & 391 & 385 & 1406 & 109 & 117 \\
\hline $\mathrm{B}\left(6-\mathrm{OH}^{\mathrm{B}}\right)$ & & & & 391 & 390 & 382 & 1383 & 99 & 105 \\
\hline B(7-OH) & & & & 328 & 316 & 309 & 1377 & 106 & 108 \\
\hline B(3-H) & & & & 387 & 378 & 376 & 1390 & 121 & 119 \\
\hline B (8-H) & & & & 429 & 427 & 425 & 1533 & 269 & 264 \\
\hline
\end{tabular}
for the energetically preferred conformations.

*Starting geometry does not include hydrogen bond between $\mathrm{C} 4 \mathrm{OH}$... OC7 atomic pair. 
for the conformation with one intramolecular hydrogen bond (see Fig. 1). The calculated gas-phase values for deprotonated hydroxyl groups range from $1305 \mathrm{~kJ} \mathrm{~mol}^{-1}$ to $1472 \mathrm{~kJ} \mathrm{~mol}^{-1}$. Similarly, as in the case of homolytic dissociation of the hydroxyl group, the energetically preferred dissociation is in the vicinity of the double carbon-carbon bond. The inclusion of solvent leads to rapid decrease of proton affinities; B3LYP values change from $67 \mathrm{~kJ} \mathrm{~mol}^{-1}$ to $169 \mathrm{~kJ} \mathrm{~mol}^{-1}$ (SMD) and $61 \mathrm{~kJ} \mathrm{~mol}^{-1}$ to $179 \mathrm{~kJ} \mathrm{~mol}^{-1}$ (IEF-PCM). Theoretical calculations for the AA molecule predict deprotonation as more energetically preferable for the 4-OH than for the 3-OH group. A possible explanation is related to the effect of $\pi$-electron conjugation occurring along the trans-oriented bonds $\mathrm{O}=\mathrm{C} 2-\mathrm{C} 3=\mathrm{C} 4-\mathrm{OH}$. In general, such conjugated groups are more likely to deprotonate (Wyman, 1955).

Formation of molecule $\mathbf{A}$ anion is most convenient through tertiary $\mathbf{A}(\mathbf{5}-\mathbf{H})$ group $\left(80 \mathrm{~kJ} \mathrm{~mol}^{-1}\right.$ in solvent). Hydrogen atom at the $\mathrm{C} 5$ atom $(5-\mathrm{H})$ is more acidic than the other hydroxyl groups due to the classic withdrawing effect of three neighboring keto groups present in the molecule. Also, $P A$ values of chain $\mathbf{A}(\mathbf{6}-\mathbf{O H})$ and $\mathbf{A}(\mathbf{7}-\mathbf{O H})$ groups show differences; the latter one is energetically preferred due to steric effects. In case of molecule $\mathbf{B}$, both $\mathbf{B}(6-\mathbf{O H})$ groups show the lowest values of $P A$. Comparing tertiary $\mathbf{B}(\mathbf{3}-\mathbf{H})$ and $\mathbf{B}(\mathbf{8}-\mathbf{H})$ groups, the first exhibits lower $P A$ value due to the presence of a hydroxyl group at the $s p^{3} \mathrm{C} 3$ atom.

From the experimental point of view, the acid dissociation constant, or its logarithmic expression $\left(\mathrm{p} K_{\mathrm{a}}\right)$, represents a quantitative measure of heterolytic dissociation in solution. The value of $\mathrm{p} K_{\mathrm{a}}$ for water can be calculated from the Gibbs energies:

$$
\begin{gathered}
\mathrm{p} K_{\mathrm{a}}=\left[\Delta G_{\mathrm{aq}}\right] /(2.303 R T)= \\
=\left[G_{\mathrm{aq}}\left(\mathrm{A}^{-}\right)+G_{\mathrm{aq}}\left(\mathrm{H}^{+}\right)-G_{\mathrm{aq}}(\mathrm{HA})\right] /(2.303 R T)
\end{gathered}
$$

where $G_{\mathrm{aq}}\left(\mathrm{A}^{-}\right)$represents Gibbs free energy of anion, $G_{\mathrm{aq}}\left(\mathrm{H}^{+}\right)$is total Gibbs free energy of proton $\left(-1104.62 \mathrm{~kJ} \mathrm{~mol}^{-1}\right)$ (Alongi et al., 2010), and $G_{\mathrm{aq}}(\mathrm{HA})$ is total Gibbs free energy of the molecule. Symbol $R$ stands for the gas constant and $T$ is temperature. The calculated reaction Gibbs free energies $\left(\Delta G_{\mathrm{aq}}\right)$ and evaluated $\mathrm{p} K_{\mathrm{a}}$ values in water are collected in Table 3 .

The lowest predicted $\mathrm{p} K_{\mathrm{a}}$ value of reference vitamin $\mathrm{C}$ is 6.1 (IEF-PCM) and 7.3 (SMD) and it is related to the deprotonation of the 4-OH group. The reported experimental $\mathrm{p} K_{\mathrm{a}}$ values of this weak dibasic acid are 4.25 and 11.79 (Combs, 2008). Probably the lower experimental acidity of deproteinized ascorbic acid is related to the occurrence of resonance structures of the ascorbate anion and the natural limitations of the implicit cavity solvent model. In case of dehydro- ascorbic acid (A), the lowest $\mathrm{p} K_{\mathrm{a}}$ values of 8.7 (SMD) and 9.3 (IEF-PCM) are due to the proton abstraction from the $\mathrm{C} 5$ atom. The reported experimental value measured in water is $\sim 9$ (Gutierrez, 1988). Unfortunately, their used experimental technique was not able to identify the abstracted bond. Consequently, compared with the available experimental data, proton abstraction from $\mathrm{C} 5-\mathrm{H}$ is the most probable. Influence of keto groups present in the molecule was assumed. It seems that the SMD model overtakes IEF-PCM model by giving the results in better compliance with literature. For molecule $\mathbf{B}$, the lowest $\mathrm{p} K_{\mathrm{a}}$ values are 13.1 (SMD) and 13.7 (IEF-PCM) corresponding with general $\mathrm{p} K_{\mathrm{a}}$ values of aliphatic alcohols (Takahashi et al., 1971). The lowest value is related to the proton abstraction from the $\mathbf{6}-\mathbf{O H}^{\mathbf{B}}$ hydroxyl group, but the differences between the theoretical $\mathrm{p} K_{\mathrm{a}}$ values for $\mathrm{C} 3-\mathrm{H}$ and $6 \mathrm{O}-\mathrm{H}^{\mathrm{A}}$ are minimal. Therefore, in sufficiently basic environment, the possibility of heterolytic dissociation from the mentioned tertiary hydrogen occurs. On the other hand, C8-H group does not share a carbon atom with a hydroxyl group and thus higher $\mathrm{p} K_{\mathrm{a}}$ of 42.4 was measured (SMD). The value is regular for tertiary bonds in cyclic organic compounds (Shen et al., 2007).

Tab. 3. Reaction Gibbs energies and $\mathrm{p} K_{\mathrm{a}}$ values

\begin{tabular}{|c|c|c|c|c|}
\hline & \multicolumn{2}{|c|}{$\Delta G / \mathrm{kJ} \mathrm{mol}^{-1}$} & \multicolumn{2}{|c|}{$\mathrm{p} K_{\mathrm{a}}$} \\
\hline & SMD & IEF-PCM & SMD & IEF-PCM \\
\hline $\mathbf{A A}(3-O H)$ & 85.1 & 94.8 & 14.9 & 16.6 \\
\hline $\mathbf{A A}(4-\mathbf{O H})$ & 41.8 & 35.0 & 7.3 & 6.1 \\
\hline $\mathbf{A A}(6-O H)$ & 136.0 & 152.7 & 23.8 & 26.7 \\
\hline $\mathbf{A A}(7-\mathbf{O H})^{*}$ & 163.7 & 187.0 & 28.7 & 32.8 \\
\hline $\mathbf{A A}(5-H)$ & 168.4 & 168.9 & 29.5 & 29.6 \\
\hline $\mathrm{A}(6-\mathrm{OH})$ & 123.9 & 139.4 & 21.7 & 24.4 \\
\hline $\mathbf{A}(7-\mathrm{OH})$ & 63.3 & 70.5 & 11.1 & 12.4 \\
\hline$A(5-H)$ & 49.6 & 52.7 & 8.7 & 9.3 \\
\hline В(3-OH) & 129.9 & 127.3 & 22.8 & 22.3 \\
\hline $\mathrm{B}\left(6-\mathrm{OH}^{\mathrm{A}}\right)$ & 84.9 & 92.0 & 14.9 & 16.1 \\
\hline $\mathrm{B}\left(6-\mathrm{OH}^{\mathrm{B}}\right)$ & 74.9 & 78.5 & 13.1 & 13.7 \\
\hline В(7-OH) & 83.6 & 85.2 & 14.7 & 14.9 \\
\hline B(3-H) & 93.8 & 90.3 & 16.4 & 15.8 \\
\hline B(8-H) & 242.3 & 236.8 & 42.4 & 41.5 \\
\hline
\end{tabular}
calculated for water environment.

"Starting geometry does not include hydrogen bond between $\mathrm{C} 4 \mathrm{OH}$... OC7 atomic pair.

\section{Conclusion}

Conformation analysis of dehydroascorbic acid and its bicyclic form was performed using the B3LYP DFT functional for the gas-phase and two implicit 
solvent models, i.e., IEF-PCM and SMD. For the energetically preferred conformations, the bond dissociation enthalpies, ionization potentials and proton affinities were calculated; values of $\mathrm{p} K_{\mathrm{a}}$ were predicted for water environment. Theoretical results indicate that the investigated bicyclic metabolic products of vitamin $\mathrm{C}$ can possess small radical scavenging ability. Furthermore, our calculations for vitamin $\mathrm{C}$ and dehydroascorbic acid indicate that, from the thermodynamic point of view, the preferable way of homolytic and heterolytic dissociation includes the $\mathrm{C}-\mathrm{H}$ bond. Therefore, the antioxidant activity mechanism of L-ascorbic acid and its oxidated form should be possible through bonds of tertiary hydrogen groups.

\section{Acknowledgement}

The work has been supported by the Slovak Research and Development Agency (APVV-15-0053) and VEGA $1 / 0504 / 20$ and $1 / 0461 / 21$. We are grateful to the HPC centre at the Slovak University of Technology in Bratislava, which is a part of the Slovak Infrastructure of High Performance Computing (SIVVP project, ITMS code 26230120002, funded by the European Region Development Funds, ERDF) for the computational time and resources made available. Authors would like to thank Dr. Martin Michalik for his technical support and discussion.

\section{References}

Alongi KS, Shields GC (2010) Ann. Rep. Comp. Chem. 6: 113-138.

Becke AD (1988) Phys. Rev. A 38: 3098-3100.

Bendich A, Langseth L (1995) J. Am. Coll. Nutr. 14: 124-136.

Bielski BHJ, Allen AO, Schwarz HA (1981) J. Am. Chem. Soc. 103: 3516-3518.

Bielski BHJ, Cabelli DE, Arudi RL, Ross AB (1985) J. Phys. Chem. Ref. Data 14: 1041-1100.

Binkley JS, Pople JA, Hehre WJ (1980) J. Am. Chem. Soc. 102: 939-947.

Combs GF Jr., The Vitamins - Fundamental Aspects in Nutrition and Health, New York, Elsevier Academic Press, 2008, ISBN-13:978-0-12-183493-7.

Deakin MR, Kovach PM, Stutts KJ, Wightman RM (1986) Anal. Chem. 58: 1474-1480.

Fisher AJ, Ten Pas RH (1966) Anesth. Analg. 45 (5): 531-534.
Flukiger P, Luthi HP, Portmann S, Weber J (2000-2002) MOLEKEL 4.3, Swiss Center for Scientific Computing, Manno Switzerland.

Frisch MJ, Trucks GW, Schlegel HB, Scuseria GE, Robb MA, Cheeseman JR, Scalmani G, Barone V, Petersson GA, Nakatsuji H, Li X, Caricato M, Marenich AV, Bloino J, Janesko BG, Gomperts R, Mennucci B, Hratchian HP, Ortiz JV, Izmaylov AF, Sonnenberg JL, Williams-Young D, Ding F, Lipparini F, Egidi F, Goings J, Peng B, Petrone A, Henderson T, Ranasinghe D, Zakrzewski VG, Gao J, Rega N, Zheng G, Liang W, Hada M, Ehara M, Toyota K, Fukuda R, Hasegawa J, Ishida M, Nakajima T, Honda Y, Kitao O, Nakai H, Vreven T, Throssell K, Montgomery JA Jr., Peralta JE, Ogliaro F, Bearpark MJ, Heyd JJ, Brothers EN, Kudin KN, Staroverov VN, Keith TA, Kobayashi R, Normand J, Raghavachari K, Rendell AP, Burant JC, Iyengar SS, Tomasi J, Cossi M, Millam JM, Klene M, Adamo C, Cammi R, Ochterski JW, Martin RL, Morokuma K, Farkas O, Foresman JB, Fox DJ (2016) Gaussian 16, Revision B.01, Gaussian, Inc., Wallingford CT.

Gutierrez PL (1988) Drug Met. Rev. 19: 319-343.

Lengyel J, Rimarčík J, Vagánek A. Fedor J, Lukeš V, Klein E (2012) Food. Chem. 133: 1435-1440.

Kurata T, Nishikawa Y (2000) Biosci. Biotechnol. Biochem. 64: 1651-1655.

Lee C, Yang W, Parr RG (1988) Phys. Rev. B 37: 785-789.

Merenich AV, Cramer CJ, Truhlar DG (2009) J. Phys. Chem. B 113: 6378-6396.

Michalik M, Lukeš V (2016) Ac. Chim. Slov. 9: 89-94.

Njus D, Kelley PM, Tu YJ, Schlegel HB (2020) F. Rad. Bio. Med. 159: 37-43.

Pandithavidana DR, Jayawardana SB (2019) Molecules 24: 1646 .

Rimarčík J, Lukeš V, Klein E, Ilcin M (2010) J. Mol. Struct. 952: 25-30.

Shen K, Fu Y, Li JN, Liu L, Guo QX (2007) Tetrahedron 63: $1568-1576$.

Škorňa P, Lengyel J, Rimarčík J, Klein E (2014) Comp. Theor. Chem. 1038: 26-32.

Takahashi S, Cohen LA, Miller HK, Peake EG (1971) J. Org. Chem. 36: 1205-1209.

Tomasi J, Mennucci B, Cammi R (2005) Chem. Rev. 105: 2999-3093.

Tu YJ, Nius D, Schlegel HB (2017) Org. Biomol. Chem. 15: 4417-4431.

Warren JJ, Tronic TA, Mayer JM (2010) Chem. Rev. 110: 6961-7001.

Wilson JX (2002) FEBS Lett. 527: 5-9.

Wyman GM (1955) Chem. Rev. 55: 625-657. 